\title{
NARRATIVAS DOCENTES E CRIAÇÃO CURRICULAR, DESAFIOS DE TEMPOS PANDÉMICOS
}

\author{
Graça Regina Franco da Silva Reis \\ Universidade Federal do Rio de Janeiro - UFRJ, Brasil \\ Marina Santos Nunes de Campos \\ Universidade Federal do Rio de Janeiro - UFRJ, Brasil \\ Ilana Maria Martins \\ Universidade Federal do Rio de Janeiro - UFRJ, Brasil
}

\begin{abstract}
Resumo
Este texto objetiva apresentar a Pesquisa que vimos desenvolvendo no período pandêmico com professores/as sobre as suas produções curriculares. Nesse sentido, provocamos a pensar sobre os dispositivos de regulação que permeiam a docência e os currículos que são atravessados pelo que acontece no miúdo dessa escola que hoje, em função da pandemia de COVID-19, se desenha ou redesenha por necessidade de existir e resistir. Apontamos que a criação curricular cotidiana acontece de diversas outras formas que não aquelas pretendidas pelas políticas de currículo e formação atuais pelas mãos de milhares de professores/as que teimam em produzir conhecimentos com seus estudantes, apesar da precariedade a que, por vezes, seu trabalho é submetido. Tomadas pelo desejo de compreender essa escola sem chão e toda a produção que nela se dá mesmo sem sua estrutura física, escolhemos trabalhar com a pesquisa narrativa, compreendendo que esta nos ajuda a conhecer o que vem sendo produzido, além de permitir que também possamos dialogar com estas práticas a partir de nossas vivências também narradas.
\end{abstract}

Palavras-chave: Criação curricular; Pandemia; Narrativas.

\begin{abstract}
This text aims to present the research we have been developing in the pandemic period with teachers about their curricular productions. In this sense, we provoke to think about the regulation devices that permeate the teaching and the curricula that are crossed by what happens in this school that today, due to the pandemic of COVID-19, draws or redesigns itself by necessity to exist and resist. We point out that the daily curricular creation happens in many other ways than those intended by the current curriculum and training policies by the hands of thousands of teachers who insist on producing knowledge with their students, despite the precariousness to which their work is sometimes subjected. Taken by the desire to understand this school without solid bases and all the production that takes place in it even without its physical structure, we chose to work with narrative research, understanding that it helps us to know what has been produced, besides allowing us to dialogue with these practices from our own experiences, also narrated.
\end{abstract}

Keywords: Curriculum creation; Pandemic; Teachers' narratives.

ISSN 1645-1384 (online) www.curriculosemfronteiras.org 


\section{Introdução ao tema: que tempos são esses?}

O colonialismo visível te mutila sem disfarce: te proíbe de dizer, te proíbe de fazer, te proíbe de ser. O colonialismo invisível, por sua vez, te convence de que servidão é um destino, e a impotência, a tua natureza: te convence de que não se pode dizer, não se pode fazer, não se pode ser (GALEANO, 2009, p.157)

A escolha de uma citação de Galeano para iniciarmos nosso texto, apresenta indícios de que, na verdade, a crise que enfrentamos com a pandemia de coronavírus não foi inaugurada pelo vírus, mas sim intensificada.

Vimos assistindo, bem antes da chegada do vírus, por vezes boquiabertos, discursos voltados para a educação pública brasileira que ou são reflexos de uma crise ou buscam instaurá-la. As Fake News transbordam pelas redes sociais disputando status de verdades indiscutíveis, mesmo quando se apresentam de forma claramente absurda, como no caso de uma tal mamadeira que vinha sendo distribuída nas escolas. Como pode alguém que frequentou a escola em algum momento da vida, seja ele próprio, ou por meio de seus filhos, netos, sobrinhos, acreditar num absurdo como esse?

Tais narrativas, que até pouco tempo atrás seriam consideradas delírios, encontram solo fértil em um tempo de democracia fraturada, na qual as instituições, como as universidades e as escolas, produtoras de ciência e outros conhecimentos estão sendo fortemente atacados e desqualificados.

Com essa tática de desqualificar, negar e vigiar surgem movimentos que funcionam como dispositivos de regulação docente, como o Escola sem Partido que, mesmo sem base legal, torna o cotidiano docente, muitas vezes, insuportável com suas denúncias e ataques ao conhecimento crítico. Fora isso, temos políticas de currículo que se constituem a partir da desqualificação do saber docente, na medida em que buscam padronizar fazeres e avaliações sob o pretexto de que os docentes nada sabem, como a Base Nacional Comum-formação e a Base Nacional Comum Curricular, para citar apenas duas.

Como dito na epígrafe, tudo isso junto, nos parece um trabalho de convencimento. Um convencimento de que nada se pode fazer, nem ver, nem dizer e nem ser. É necessário subverter esta "ordem" invisível. É preciso ver, falar, denunciar.

Esses dispositivos de regulação somados à pandemia da COVID-19 que nos assola desde março de 2020, nos permite dizer que temos vivido um desafio sem tamanho.

Para que a pandemia pudesse ser contida houve a necessidade de isolamento social, as escolas, assim como vários outros estabelecimentos, foram fechadas. O coronavírus nos deixou sem nenhuma compreensão do que estávamos a viver. Sabíamos, no entanto, que a luta em prol da desqualificação docente, das escolas e das universidades públicas, estava a ganhar espaço pois, ao precisarmos atuar junto aos estudantes de forma remota num país em que a desigualdade social prevalece, sabíamos da impossibilidade de pensarmos em uma atuação igualitária, democrática entre as crianças e jovens desse país, pois, em sua maioria, a internet somada a equipamentos adequados ao ensino remoto, são um luxo ao qual não podem se dar. 
Após o tempo de tentar entender o que se passava, foi necessário assentar os pés no chão e perguntar: como atravessaremos esses tempos criando no presente possibilidades para um futuro que possa se desenhar mais democrático do que o agora, quando começamos a perceber o agravamento das desigualdades? Como sairemos (sairemos?) desta pandemia que se reconfigura a cada dia e nos aflige cotidianamente reafirmando o lugar da escola para todos?

Estas primeiras perguntas se esboçaram muito cedo para nós que vivemos a escola, na escola todos os dias, pois somos professoras/es e a escola, para nós, é o lugar onde tudo acontece. Isso porque sabemos que

A escola não é apenas um espaçotempo para aprender conhecimentos, delimitados em disciplinas e explicados por um mestre. "A escola é o lugar onde momentos democráticos podem acontecer" (Masschelein; Simons, 2014a, p. 106), em que os tempos podem ser interrompidos e alargados. A referida instituição coloca os saberes sociais e historicamente produzidos pela humanidade em foco, como tema/assunto de estudo e, por muitas vezes, deixa de fora outros saberes (também produzidos pela humanidade), que não são considerados válidos na perspectiva eurocêntrica. Ao materializar a relação com o conhecimento, entre professores e estudantes, a instituição escolar proporciona momentos de encontros, conversas, reflexões, análises e debates. Nesse sentido, busca promover ações na perspectiva de visibilizar outros saberes que tenham relação com a vida e interesse dos estudantes (BERTI, SOUZA, NASCIMENTO, 2021, p. 79)

A fim de pensarmos o papel da escola com as questões que a atravessam nesses tempos, reorganizamos nossa pesquisa que se dá no campo dos currículos e da formação docente, buscando pensar com as/os professoras/es, que somos nós também, quais deslocamentos metodológicos são e foram necessários ao cotidiano escolar quando o chão físico da escola não pode ser vivenciado. Alguns movimentos/desejos/indagações foram tomando forma, pois

nos vimos em uma escola sem chão, paredes e fronteiras. Sem notas, obrigatoriedade, coerção. Era necessário retomar a autonomia discente, o desejo e o afeto pelo conhecimento. Do lado dos docentes e demais profissionais, era necessário valorizar o processo de autoria no redesenho da escola. Diante da possibilidade aparentemente mais simples de pegar o atalho da transposição do que fazíamos para o que faríamos, escolhemos a realização de um trabalho que revisava os sentidos do conhecer. Nesse processo, percebemo-nos ao mesmo tempo, agentes - pela possibilidade de propor - e agenciados - por práticas fortemente estabelecidas e, aparentemente, imutáveis (MENEZES, 2021, p. 54)

Nesse sentido, se por um lado a pandemia nos trouxe sofrimentos incalculáveis, por outro criou um hiato que nos permitiu pensar sobre os dispositivos de regulação que permeiam a docência e os currículos que são atravessados pelo que acontece no miúdo dessa escola que hoje, em função da pandemia de COVID-19, se desenha ou redesenha por necessidade de 
existir e resistir. Essa escola acontece de diversas outras formas pelas mãos de milhares de professoras/es que teimam em produzir conhecimentos com seus estudantes apesar da precariedade a que, por vezes, seu trabalho é submetido.

Tomadas pelo desejo de ampliar a compreensão dessa escola sem chão e toda a produção que nela se dá mesmo assim, escrevemos este texto que tem o objetivo de apresentar a Pesquisa que vimos desenvolvendo no período pandêmico com professoras/es sobre as suas produções curriculares.

Escolhemos trabalhar com a pesquisa narrativa compreendendo que esta nos ajuda a conhecer o que vem sendo produzido, além de permitir que também possamos dialogar com estas práticas a partir de nossas vivências também narradas.

\section{A narrativa como possibilidade de pensar/conhecer/ressignificar os currículos em tempos pandêmicos}

Em Montevidéu, no bairro Braço Oriental: Estamos aqui sentados, vendo como matam os nossos sonhos. E, no cais na frente do porto de Buceo, em Montevidéu: Bagre velho: não se pode viver com medo a vida inteira. Em letras vermelhas, ao longo de um quarteirão inteiro da avenida Cólon, em Quito: E se nos juntarmos para dar um chute nesta grande bolha cinzenta? (GALEANO, 2009, p.163)

Vimos desenvolvendo um Projeto que se inscreve na articulação entre pesquisa e extensão, dando origem à uma produção acadêmica sobre os estudos com os currículos e com a formação docente a partir do espaçotempo ${ }^{1}$ das conversas. Assim como Coutinho (1997), preferimos o termo conversa ao termo entrevista, porque o que fazemos nos cotidianos, com as/os professoras/es, é trocar experiências. Coutinho afirma que,

toda a filmagem - e acredito que na história oral isso exista também, mas de uma forma mais amena, mais simples, mais implícita - tem que ser negociada. (...) Essa negociação que preside a muitas entrevistas e depoimentos - prefiro chamar de conversas, porque entrevista, depoimento, pressupõe uma formalização que destrói o clima de diálogo espontâneo que é importante - não está jamais na perspectiva, por exemplo, da televisão e da maioria dos documentários (COUTINHO, 1997, p. 166).

As conversas têm nos apresentado a narrativas que nos desafiam a (re)pensar as experiências vividas com a produção de conhecimentos que se dá no cotidiano das escolas. No processo de conversar, partilhamos e esse compartilhamento (auto)forma os sujeitos, pois cada experiência vivida nesse compartilhar tem a possibilidade de mexer com as nossas redes de aprendizagens, abalando nossa zona de conforto e nos ajudando a ver como na poesia de Galeano (2009). 
Diego não conhecia o mar. O pai, Santiago Kovadloff, levou-o para que descobrisse o mar. Viajaram para o Sul. Ele, o mar, estava do outro lado das dunas altas, esperando. Quando o menino e o pai enfim alcançaram aquelas alturas de areia, depois de muito caminhar, o mar estava na frente de seus olhos. E foi tanta a imensidão do mar, e tanto fulgor, que o menino ficou mudo de beleza. E quando finalmente conseguiu falar, tremendo, gaguejando, pediu ao pai: Me ajuda a olhar! (p. 15)

Nesse processo (auto)formativo temos experienciado pensar/conhecer/ressignificar os currículos que são produzidos nos miúdos das salas de aula e, com esse movimento, que é coletivo, conhecemos e nos damos a conhecer, pois a conversa possibilita pensar com o Outro (MATURANA, 1999), num processo de escutas, aprendizagens, estranhamentos, aproximações, distanciamentos, onde temos a possibilidade de compreender que o Outro é apenas Outro diferente de nós e que seus conhecimentos, no caso da docência, conhecimentos pedagógicos, são legítimos.

A narrativa tem nos possibilitado esses encontros e, ao investirmos nossa produção e pesquisa em torno dela, dialogamos com diversos pesquisadores do campo da educação que tem optado pela pesquisa narrativa como campo de conhecimento.

Alves (2008) nos indica que a narrativa é uma das artes mais importantes para compreensão das práticas cotidianas, pois é a forma como diferentes sujeitos do cotidiano contam suas experiências a outros, seja por meio da fala ou escrita. Dessa forma, contam suas histórias, possibilitando uma melhor compreensão da complexidade na qual se desenha o cotidiano.

No mesmo sentido, para Certeau (1994),

A narrativização das práticas seria uma 'maneira de fazer' textual, com seus procedimentos e táticas próprios. A partir de Marx e Freud (para não remontar mais acima), não faltam exemplos autorizados. Foucault declara, aliás, que está escrevendo apenas histórias ou 'relatos'. Por seu lado, Bourdieu toma relatos como a vanguarda e a referência de seu sistema. (...) Não seria necessário reconhecer a legitimidade 'científica' supondo que em vez de ser um resto ineliminável ou ainda a eliminar do discurso, a narratividade tem ali uma função necessária, e supondo que 'uma teoria do relato é indissociável de uma teoria das práticas', como a sua condição ao mesmo tempo que sua produção? (...) Isto seria sobretudo restituir importância 'científica' ao gesto tradicional (é também uma gesta) que sempre 'narra' as práticas. Neste caso, o conto popular fornece ao discurso científico um modelo, e não somente objetos textuais a tratar. Não tem mais o estatuto de um documento que não sabe o que diz, citado à frente de e pela análise que o sabe. Pelo contrário, é um 'saber-dizer' exatamente ajustado a seu objeto e, a este título, não mais o outro do saber mas uma variante do discurso que sabe e uma autoridade em matéria de teoria. (CERTEAU, 1994, p. 152, 153).

Para Souza (2012), as narrativas se configuram, "no campo educacional, em diálogo com outras áreas do conhecimento, como possibilidade teórico-metodológica de pesquisas 
que buscam apreender modos como os sujeitos narram suas histórias individuais ou coletivas" (p.61). Para o autor, narrativa é uma abordagem de investigação-formação "porque parte das experiências advindas da vida humana e possibilitam, mediante a reflexividade biográfica, apreender dimensões cotidianas da vida" (p.61).

Com Benjamin (1987), aprendemos que narrar é intercambiar experiência. O narrador de Benjamin é "aquele que retira das experiências o que ele conta: sua própria experiência ou relatada pelos outros. E incorpora as coisas narradas às experiências de seus ouvintes" ( $p$. 201).

Partindo desses pressupostos, compreendemos o uso das narrativas como forma de desinvisibilização dessas experiências curriculares, ou seja, experiências que estão lá, sendo produzidas, mas muitas vezes não são enxergadas ou são descredibilizadas por uma lógica monocultural e hegemônica (SANTOS, 2010), que está intrínseca à concepção moderna de escola. Essa concepção trabalha sempre com a ideia de que a escola deveria fazer algo que não faz e que isso é comprovado pelos resultados das grandes avaliações nacionais e internacionais.

Por meio das narrativas, podemos sair desse lugar de uma escola idealizada que não é o que deveria, mas sim, que faz, acontece e produz currículos e conhecimentos a todo o tempo. Esse compartilhamento que buscamos proporcionar por meio das conversas nos fazem conhecer experiências e práticas curriculares locais que proporcionam legitimação a toda essa produção autoral. As narrativas são assim, tomadas como experiências formativas porque partimos do pressuposto de que a formação se dá continuamente, ou seja, é um processo que começa com o nascimento e se tece por toda a vida dos sujeitos (CAMPOS, REIS, 2019), como já apontado por Souza (2012), um processo de investigação-formação.

Apostamos que, quando uma/um professora/r narra suas experiências e sua narrativa é compartilhada, toda a categoria profissional docente ganha, pois no processo há o (re)conhecimento de que o que acontece nas escolas tem relevância, muito para além do que pensamos saber sobre elas. Há aí, ou esperamos que haja, um reconhecimento da docência em sua profissionalidade como produtora de conhecimentos diversos sobre as escolas, os currículos e a formação docente.

As narrativas de experiências curriculares são consideradas por nós um gênero específico, denominado de narrativas pedagógicas (PRADO, FERREIRA, FERNANDES, 2011, p. 145) que estão carregadas de diversos saberes sobre a complexidade dos cotidianos escolares. Assim,

Temos defendido que, dentre a diversidade de gêneros discursivos, são privilegiados para esse tipo de registro as 'narrativas pedagógicas' - textos predominantemente narrativos e autobiográficos, escritos para compartilhar lições aprendidas a partir da experiência, da reflexão sobre a experiência, da observação da prática dos pares, da discussão coletiva, da leitura, do estudo e da pesquisa. Incluímos na 'família' das narrativas pedagógicas em especial os memoriais, as novelas de formação, as cartas pedagógicas, as crônicas do cotidiano, os depoimentos, os diários, os relatos de experiência e de pesquisa - gêneros 
discursivos privilegiados para que os educadores documentem o que fazem, o que pensam, o que pensam sobre o que fazem, assim como suas inquietações, dificuldades, conquistas, sua produção intelectual (PRADO, FERREIRA, FERNANDES, 2011).

Nesse sentido, a pesquisa que vimos desenvolvendo compreende como narrativa pedagógica tudo aquilo que partilhamos narrando as experiências vividas. A narração que chega por e-mail, pelo WhatsApp, as conversas nas plataformas digitais, tudo aquilo que conta sobre o que é produzido cotidianamente nas experiências da/na escola entre professoras/es e estudantes.

A partir desse manancial de narrativas que ouvimos, vemos, lemos e escrevemos, temos entendido ser importante criar formas de compartilhamento que possam proporcionar um reconhecimento do outro e de suas experiências por um maior número de professoras/es. Assim, temos nomeado de materiais narrativos a produção que temos conseguido organizar.

Para isso, a partir das memórias e experiências narradas, temos produzido uma série de materiais biográficos - artigos, memoriais e livros com narrativas - e mais recentemente vimos investindo na produção de materiais audiovisuais - fotos, vídeos - que tem nos ajudado a fortalecer e reconhecer esse lugar de autoria nas produções curriculares que têm sido compartilhadas. Tal produção é artesanal, cuidadosa, ética e que reforça a ideia de autoria, solidariedade e pertencimento.

Com isso em mente, temos agido a partir de três frentes. A primeira se dá pela filmagem/gravação de todos os encontros com professoras/es nos cursos de extensão promovidos pelo grupo de pesquisa e agora realizados por meio de plataforma digital. A segunda frente realizando sessões de conversa em que docentes narram experiências curriculares e histórias de vida e a terceira que se dá por meio do envio através de diferentes canais de narrativas que têm sido organizadas e compartilhadas por meio do site do Projeto.

O compartilhamento de narrativas nas rodas de conversa, nos vídeos produzidos e no espaço das escolas em que atuamos tem sido fundamental para a pesquisa realizada pelo grupo, pois serve como material empírico que apoia os estudos que vimos realizando coletivamente. Temos percebido que muitas das narrativas produzidas convergem para uma criação curricular cotidiana (OLIVEIRA, 2013) e que esta criação, se compartilhada, gera outras produções e reconfigurações (CAMPOS; REIS, 2019, p. 401).

Esse movimento tem nos ajudado a compreender que as produções curriculares são singularessociais. Ou seja, toda essa produção é resultado singular daquilo que se produz a partir de crenças, aprendizagens e valores, que se tecem em nossas redes que são sempre sociais, pois vivemos, aprendemos, ensinamos somente na interação com o Outro.

Ouvir o Outro, seja ele/a estudante ou docente como legítimo, entendendo que produzimos currículos sempre por meio da partilha, nos ajuda a entender que qualquer produção de conhecimento acontece por meio da interação.

Assim, aprendemos que este movimento de tessitura singularsocial cotidiana de criação de currículo é potente e se traduz em esperançar numa perspectiva freireana, porque viver o presente, construindo nele cotidianamente uma educação solidária e democrática, educando 
na cidadania, na solidariedade, pode nos permitir viver no futuro uma educação solidária e democrática, pois "existe um único lugar onde o ontem e o hoje se encontram e se reconhecem e se abraçam, e este lugar é o amanhã" (GALEANO, 2009, p.133).

\section{Para além das regulações, uma conversa sobre perspectivas curriculares}

Como discutido, os discursos que buscam desqualificar a docência e práticas escolares, notadamente das escolas públicas e seus sujeitos, acusando-as de serem ineficientes e tendenciosas, apontam os "pacotes" como solução para os problemas enfrentados pela educação, algo que têm se mostrado um mercado muito lucrativo. Isso que chamamos de pacotes compreendem materiais didáticos, formações continuadas e avaliações, tudo sempre formulado de fora da escola, tomando a padronização e controle do chão da escola como receita de sucesso.

Cabe ressaltar que, embora nas políticas públicas e discursos midiáticos este pensamento herdado da lógica empresarial tenha muito espaço, o pensamento curricular há muito já discute a não neutralidade dos currículos e a impossibilidade de um currículo formal ser aplicado automaticamente nas salas de aulas.

Sendo assim, neste texto, nos esquecemos da acepção de currículo como uma listagem formal de conteúdos e compreendemos o currículo como o resultado, sempre provisório, de negociações entre o que é imposto pelo poder instituído aos praticantes das escolas e o que lhes é possível e credível (OLIVEIRA, 2012) tecer a partir das normas em sua relação com as possibilidades do real. Ou seja, nesse movimento de uso dos produtos, professoras/es e alunos vão "dando vida" aos currículos, a partir de seus modos de fazerpensar e criam e recriam soluções/ saberes/ práticas cotidianamente.

Esse ineditismo dos currículos pensadospraticados ${ }^{2}$, por vezes, é tomado apenas como desvio do currículo prescrito. No entanto, compreendemos que os primeiros são muito mais ricos, complexos e completos que os segundos, porque professoras/es buscam assegurar aos seus alunos, para além das aprendizagens contidas nas propostas oficiais, uma "formação global, de educação para além do ensino, no sentido de promover aquilo que acreditam ser uma educação de qualidade para seus alunos". Com essa intencionalidade "incluem muitos outros conhecimentos, expressam e negociam valores morais, sociais, políticos; incluem as relações entre os diferentes atores/autores do cotidiano em que se inscrevem", a partir de "negociações, diálogos, conflitos entre suas próprias convicções, crenças e possibilidades e aquilo que lhes é, a princípio, imposto pelo poder instituído" (OLIVEIRA, 2013, p. 191192).

Sendo assim, os currículos pensadospraticados (OLIVEIRA, 2012) englobam uma diversidade de experiências e saberes muito mais amplos do que o currículo oficial propõe, na medida em que são criados e usados pelos diversos sujeitos que tecem os cotidianos escolares, entrelaçando as normas com suas vidas e valores. Isso quer dizer que, mediante um conteúdo que deve ser ensinado, e voltando-se para o imperativo de planejar experiências 
que visam essa intencionalidade, o docente enreda tais conteúdos com seus conhecimentos e critérios precedentes, que englobam muito mais que apenas o conteúdo como, por exemplo, o embasamento a partir de aulas anteriores que deram mais ou menos certo, a preocupação em garantir o caráter lúdico, o conhecimento que tem sobre o grupo para qual leciona e etc. Posteriormente, quando a aula acontece, há outros diálogos e entrelaçamentos, visto que o momento planejado não chega em um terreno vazio, pois mesmo crianças pequenas possuem suas redes de conhecimentos e subjetividades que interagem com a proposta, o que implica em imprevisibilidade, complexidade e riqueza dos currículos pensadospraticados.

\section{Ampliando o presente e contraindo o futuro}

Partindo da noção de currículo aqui já estabelecida e voltando para a discussão do contexto pandêmico, nós docentes, que já assistimos há algum tempo essa onda padronizante e esterilizante na educação, com o advento da pandemia, imaginávamos que surgiriam pacotes e mais pacotes assim que deixássemos nossas escolas. Os meses se passaram e, surpreendentemente, não nos foi submetido nenhum material didático, nenhum manual, nenhuma avaliação externa...

Diante do inédito e do que parecia ser impossível; tecer uma escola sem escola; notamos o silêncio das instituições que costumam regular a docência e as práticas curriculares, por meio de seus dispositivos, indicando pseudo soluções para a educação. Perante isso, ficamos, por um curto espaço de tempo, em casa sem saber o que fazer e prever. Passado este torpor, ao invés de medidas padronizadas, observamos o pulular de diferentes alternativas curriculares locais para a situação.

Acreditamos que não poderia ser diferente, isso porque, embora a pandemia seja global, os impactos locais ocasionados por ela são diversos, demandando soluções locais. Dessa maneira, cada rede, cada escola, cada estudante, cada docente, cada família precisou se voltar para os limites e possibilidades do seu contexto para ser possível a criação de alternativas, nos remetendo à ideia de que problemas globais demandam soluções locais (SANTOS, 2010).

Além da dimensão do espaço para a criação dessas alternativas, tivemos que lidar, também, com a dimensão temporal, pois uma das características do contexto pandêmico é a imprevisibilidade temporal: não sabemos quando a pandemia vai acabar, se vai acabar e, além disso, a solução criada para "cobrir" três meses sem poder ir à escola não pode ser a mesma para a situação que temos agora: 17 meses de pandemia e sem previsão de fim.

Certamente o contexto pandêmico nos provoca duas grandes inseguranças, dentre tantas outras: a primeira é o medo da morte e a segunda a de não termos a mínima ideia do porvir, nenhuma perspectiva de quando poderemos voltar a pisar no chão das nossas salas de aula com segurança. A respeito dessa instabilidade, um ano antes do momento em que escrevemos este texto, em agosto de 2020, lemos e compartilhamos o seguinte relato: 
Escrever, em agosto, sobre algo que nos ocorreu em março e que virou de cabeça para baixo o modo como vivenciamos o mundo e a escola, mostrou-se uma tarefa difícil. Logo nós, professoras de criança pequenas, tão próximas do mundo da imaginação, dos contos, da brincadeira, do lúdico, não imaginávamos viver o que estamos vivendo hoje. Embora já tenhamos aprendidoensinado sobre pandemias na história da humanidade, não imaginávamos viver uma. Nós, do nosso país e do nosso tempo, que precisamos do humor para lidar com realidades por vezes tão duras, traduzimos bem o que sentimos por meio de memes e, ao pensar no que estamos vivendo, lembrei de um que dizia: "Presenciar fatos históricos cansa. Não quero mais” (QUEIROZ, REIS, CAMPOS, 2021, p. 151).

Tal desconforto, em parte, parece se dar graças ao aprendido com a razão indolente, especificamente sua face proléptica, apontada por Santos (2002), na qual o futuro é concebido a partir da monocultura do tempo linear.

Esta monocultura do tempo linear, ao mesmo tempo que contraiu o presente, como vimos atrás ao analisar a razão metonímica, dilatou enormemente o futuro. Porque a história tem o sentido e a direcção que lhe são conferidos pelo progresso, e o progresso não tem limites, o futuro é infinito. Mas porque o futuro está projectado numa direcção irreversível ele é, como bem identifica Benjamim, um tempo homogéneo e vazio (Benjamin, 1969: 261, 264). O futuro é, assim, infinitamente abundante e infinitamente igual, um futuro que, como salienta Marramao (1995: 126), só existe para se tornar passado. Um futuro assim concebido não tem de ser pensado, e é nisto que se fundamenta a indolência da razão proléptica. (SANTOS, 2002, p. 254)

Herdeiros dessa razão, nós imaginávamos ter domínio sobre o futuro, pois seria ele a repetição do presente, mas a catástrofe da pandemia nos tirou essa ilusão e fomos obrigados a pensarmos nossa atuação no presente, com o que nele havia de possibilidades, sem muitas projeções, já que toda data de retorno ao ensino presencial era adiada. Desse modo, mesmo que em um contexto tão limitante, realizamos a operação proposta por Santos, expandimos o presente e contraímos o futuro.

Buscando criar soluções para os problemas e limitações ocasionados pelo contexto pandêmico foi necessário expandir o presente, buscando nele migalhas de possibilidade, e contrair o futuro, tornando-o escasso. Ao invés de planejamentos de planos de curso anuais, foi preciso engatinhar e planejar semana a semana. Ou seja, ao invés de buscar soluções padronizantes, nos atemos a alternativas singulares.

Essas alternativas foram tecendo currículos pandêmicos que, ao serem estudados, podem nos fornecer pistas a respeito do modo pelos quais tecemos alternativas curriculares viáveis diante das questões que as diversas realidades apresentam e, ao compreendê-las, aprendermos com elas. Além disso, o contexto pandêmico evidenciou ainda mais a necessidades e o direito dos docentes terem voz e vez nos currículos (ARROYO, 2013), já que as soluções nesse contexto extremos partiram deles. 
A partir desses entendimentos, a seguir, apontamos a escuta e compartilhamento de narrativas docentes a respeito dos currículos pensadospraticados na pandemia como um procedimento metodológico ajustado para este contexto e objetivo, o de compreender os modos pelos quais os docentes pensamfazem os currículos pandêmicos.

\section{Experiências de professoras em tempos de isolamento social}

Durante a graduação, muito pensei em como seria minha primeira experiência como professora, como conduziria a turma quando chegasse a hora. Queria me sentir mais segura, li e reli inúmeros conceitos, me preparando para a docência, participei de extensões que me aproximavam da sala de aula e pude me inspirar em quem compartilhava suas práticas. No primeiro dia de aula, já atuando como professora do ensino básico, de forma remota, deparei-me com uma tela. Sem os abraços e os sorrisos que imaginei que receberia, fui ao encontro de diversos quadrados; alguns, com fundos; outros sem câmera ligada. Microfone que liga e desliga, mãos levantadas pelo aplicativo. Os primeiros dias foram difíceis tentando me adaptar. Ainda estou tentando. Tentar me descobrir como profissional, entender qual tipo de professora sou, como aprender, ensinar, partilhar através de telas. Medos e inseguranças que, provavelmente, já estariam comigo se tornaram muito maiores então, quando essa nova sala de aula era nova para todos. Perceber a inquietação das crianças, tentar lidar com as questões cotidianas ultrapassando as limitações tecnológicas, ter a dificuldade de tentar alfabetizar 16 alunos de uma forma nunca experienciada. $O$ que ameniza o processo e me conforta é o fato de não estar só. O colégio em que atuamos como docentes pratica planejamentos feitos em conjunto, numa ideia de educação interdisciplinar. Como forma de lidar com o período remoto, intensificou tal proposta, unindo, por exemplo, Língua Portuguesa a Educação Física, Matemática a Artes e Geografia a Música. No entanto, preciso também afirmar que nessas primeiras semanas pude contar com a presença de professoras/es que dividem a turma comigo, o que facilitou e me deu suporte para enredar essas relações. Sinto que é possível criar vínculos que se apresentam de formas inéditas, mas é necessário estar em constante avaliação, e, por isso, trazemos semanalmente, nossas questões cotidianas para as nossas reuniões de planejamento e, juntos, movimentamos as nossas aprendizagens e elencamos novas táticas para ressignificar os currículos expressos nessa nova sala de aula (Narrativa de Ilana Maria, 2021)

Escutar a narrativa de uma professora que no início de sua carreira se deparou com o contexto de aulas remotas, nos evoca que o seu sentimento se parece com o de todas/os as/os professoras/es que precisaram se reinventar para lidar com o desafio de pensar uma escola "sem chão". Outro aspecto que emerge da epígrafe é a constatação de que sozinhos não seria possível criar alternativas curriculares necessárias ao momento, ressaltando a dimensão coletiva da autoria docente. 
Para uma recém-professora, o trabalho coletivo parece ser acolhedor, pois a docência compartilhada configura-se como uma rede de apoio. Saber que existem pessoas elaborando em conjunto o planejamento e a própria dinâmica de sala, evidencia a importância do coletivo, afinal, ver-se como docente, em um primeiro momento, pode ser assustador, mas ter ciência de que a sensação é repartida auxilia a evitar o medo desse desconhecido.

Como mencionado, nossa Pesquisa vem se debruçando sobre as narrativas docentes a respeito de seus saberesfazeres cotidiano e, a partir do seu estudo produzimos diferentes materiais narrativos. Apostamos que ao investigarmos e desinvinsibilizarmos os currículos criados cotidianamente pelos sujeitos da escola contribuímos para a credibilização dessas experiências. Dessa maneira, durante estes tempos pandêmicos, no qual tantas escolas e coletivos docentes se dispuseram a criar novas relações e currículos, fomo imbuídos a não desperdiçarmos as aprendizagens que tal empreitada tem oportunizado e, para tal, organizamos um site e um livro que reúnem narrativas e experiências vividas no período de fechamento físico das escolas, um período em que esta encontrava-se em suspensão (CARVALHO, LEVY, 2021). O livro e o site contam com diferentes escritas narrativas de experiências pedagógicas e sociais vividas na quarentena.

Segundo Baroni (2021), em texto da primeira orelha do livro supracitado,

durante esses tempos excepcionais em que a pandemia de covid-19 engaiolou os corpos, as narrativas encontraram formas de transpor as grades. Criadas, inventadas, experimentadas, [...] elas dançam a liberdade e convidam, apesar de singulares, para o 'nós compartilhado'.

Essas narrativas presentes no livro nos convidam a conhecer as lutas, as dores, as relações, as redes de afetos e de saberes e as produções curriculares docentes tecidas na conjuntura atual, de fratura da democracia e de pandemia causada pela COVID-19. As experiências compartilhadas contam sobre a ruptura com o chão da escola, a necessidade de pensar essa escola sem chão físico e o quanto foi possível criar nessas condições inscritas em uma realidade na qual, em sua maioria, os estudantes das escolas públicas, aqueles das classes populares, não têm acesso a internet e equipamentos de qualidade para acesso às plataformas oferecidas pelas redes de ensino.

O reencontro com as narrativas e a conversa com os pares nos fazem perceber que não estamos sós, que esse processo de tessitura de alternativas se estabelece no encontro de vozes, ideias e saberes. O contexto pandêmico, ao retirar o espaço físico da escola, evidenciou algumas reflexões que podem nos ajudar a (res)significar a docência na conjuntura atual. No excerto apresentado a seguir, retirado do livro por nós organizado, a professora narra que, neste contexto:

Pudemos reforçar a importância de certas práticas, suspeitas de tantas outras e, certamente, reiterar que nós, professoras e professores, somos muito mais que transmissores de conteúdos ou aplicadores de aulas, que nossos estudantes são muito mais do que suas notas, do que sabem ou não sabem. Somos uma rede de sujeitos, repletos de afetos e sonhos e que o que fazemos na escola é muito mais 
que ensinar e aprender. No espaçotempo da escola, criamos e recriamos a nós e aos nossos mundos (CAMPOS, 2021, p. 157)

Ao defender a docência como um fazer de criação e produção curricular, a professora nos aponta que o papel da docência é também um papel de autoria, apesar dos dispositivos de buscam regular, padronizar e controlar a docência e os currículos criados cotidianamente. Além disso, ela nos indica a necessidade de conceber que os estudantes são também sujeitos autores de seus percursos de aprendizagem. Nesse sentido, a compreensão de escola vai muito além de um local de ensino e aprendizagem, significando uma rede de afetos, sujeitos e saberes.

Em outra narrativa, a professora Maria do Nascimento Silva, reflete sobre a sua trajetória como docente e as influências que a fizeram seguir esse caminho. Quanto ao enfrentamento nos tempos excepcionais vividos, ela narra acerca dos desafios de:

Pensar um currículo com as crianças tem sido desafiador tanto para mim quanto para as professoras com as quais tenho compartilhado a docência. Currículo esse que possibilite envolver a curiosidade e o interesse das crianças, como também criar condições para elas conhecerem, descobrirem e darem novos significados para suas experiências e os seus sentimentos, valorizando assim, as suas culturas e ideias. (SILVA, 2021, p.147)

Ela nos conta sobre os desafios de se trabalhar remotamente tecendo um currículo com seus estudantes, incluindo suas vozes e interesses. Afinal, como pensar nesse currículo, levando em consideração os limites que a tela impõe quando falamos do trabalho pedagógico com crianças que estão em uma fase de experimentações e vivências mais concretas. Estar na escola, em interação com os colegas e professoras/es, é uma dimensão importante no processo de ensinoaprendizagem desses estudantes. Pelas telas essas relações precisaram ser reconfiguradas, como nos indica a professora Fabiane Lima:

Nesse contexto atual, é vital acolhemos as crianças através da escuta e do afeto para ajudá-las a compreender que os momentos difíceis existem, mas que é possível enfrentá-los. Ou talvez para que elas nos ajudem nessa compreensão. É essencial, também, estarmos em conexão com as famílias para pensarmos juntos sobre a educação desses pequenos, dialogar sobre as infâncias que as constituem e, da mesma maneira, tentar entender as questões que nos abalam diante dessa pandemia. O compromisso é resguardar a vida com atenção, afeto e proteção! (LIMA, 2021, p.100)

Fabiane sublinha o afeto, a relação com as famílias e a escuta dos estudantes como dimensões essenciais do processo de ensinoaprendizagem, salientando que, neste contexto de distanciamento, cuidar desse afeto e dessas relações é ainda mais relevante. Tal narrativa também nos incita a refletir sobre o modo como os currículos tecidos pelas/os professoras/es contemplam muito mais que conteúdos disciplinares, ou seja, incluem afeto, escuta e 
acolhimento. Além disso, a professora, ao se preocupar que seus estudantes saibam observar a realidade, enfrentando-a a fim de modificá-la, incorpora a esses currículos uma série de experiências e saberes que são negligenciados por qualquer instrumento que busque reduzilos.

As experiências narradas pelas professoras exprimem a ideia da formação como resultado do encontro com o que somos e com os outros, fazendo emergir diferenças e singularidades que devem ser tratadas de forma horizontal. Partilhar histórias intensifica também redes de solidariedade, pois cria um conhecimento que, por ser publicizado, tece soluções provisórias e locais para demandas também locais.

Temos percebido que as conversas narrativas e os textos redigidos nos auxiliam a olhar e a compreender que há outros pontos de vista tão legítimos quanto os que somos capazes de enxergar, quando nos colocamos à disposição da escuta, reforçando "um sentimento de pertencimento à profissão e de identidade profissional que é importante para que se aproximem das possibilidades de reconhecimento de sua autoria e autonomia nofazerpensar docente" (REIS; OLIVEIRA, 2018, p. 70).

\section{Questões que nos atravessam, aproximando de um ponto final}

As experiências narradas e recolhidas por meio da Pesquisa que produziu o que vimos nomeando de materiais narrativos, exprime a ideia de que a criação curricular cotidiana se dá para além de quaisquer dispositivos de regulação. Essas criações têm aparecido como resultado dos encontros acontecidos no miúdo dessa escola que hoje se encontra sem um chão físico. Além disso, percebemos também que esses currículos são criados no presente, localmente, trazendo respostas, mesmo que provisórias, para questões que são globais.

Entendemos, a partir das vivências trazidas, que a escola é uma rede de afeto no sentido de afetar a todos que passam por ela. Ao partilhar histórias e trabalhar coletivamente é possível intensificar as redes de solidariedade tão importantes para a docência e seu exercício.

A pandemia, apesar de toda dor que nos trouxe, desestabilizou a compreensão do que é escola, currículo e docência, levando a novas aprendizagens sobre o fazer pedagógico, a relação com os estudantes e do que significa a escola. Com tantas suspensões foi possível reforçar a importância de certas práticas já aprendidas, suspeitar de tantas outras e, certamente, reiterar que "professoras/es são muito mais que transmissores de conteúdos ou aplicadores de aulas; que os estudantes são muito mais do que suas notas, do que sabem ou não sabem" (CAMPOS, 2021, p.162). Ou seja, somos todos uma rede de sujeitos, repletos de afetos e sonhos e o que fazemos na escola é muito mais que ensinar e aprender, na escola criamos e recriamos a nós e os nossos mundos.

O contexto atual implodiu os muros da escola, desmantelou os 50 minutos de tempo de cada disciplina, arrebentou as grades curriculares, comprimiu o ano letivo e afastou a todos fisicamente. No entanto, essas destruições inconvenientes, forçaram o repensar do tempo e do espaço escolar, do currículo, das disciplinas e das relações. 
Num retorno pós-pandemia esperamos que as tantas aprendizagens e desaprendizagens possíveis até aqui não sejam descartadas. Ter acesso às narrativas docentes que tanto ensinam quando as escutamos e compartilhamos pode ser, assim como os currículos criados nesses tempos, soluções locais para os dilemas que são vividos cotidianamente pela docência.

Por fim, após observarmos as múltiplas soluções criadas pelas diferentes escolas e seus sujeitos diante do que nos parecia insolucionável, esperamos que, de agora em diante, a lição demonstrada pelo contexto atual seja aprendida: a de que as soluções para os diversos problemas enfrentados pela educação são múltiplas, criadas no coletivo e devem partir do diálogo com os que pensamfazem as escolas cotidianamente e não por instituições, sujeitos e instrumentos que buscam pensar a escola de fora e do alto e oferecer soluções únicas, padronizantes e regulatórias.

Notas:

1. Aprendemos (pesquisadores nos/dos/com os cotidianos), com Nilda Alves, a aglutinar palavras que, pela lógica hegemônica, aparecem como estanques ou opostas. Dessa maneira, buscamos nos esquivar de possíveis dicotomias que estes conceitos carregam e abarcar novos significados para eles, seguindo o princípio da juntabilidade, como nomeia Sgarbi (2005).

2. Outros autores denominam este currículo como currículos em redes (Alves, 2001), ou currículo realizado (Ferraço,2003), ou ainda, currículo real, como é o caso de Sacristán (1995).

\section{Referências}

ALVES, Nilda. Sobre movimentos das pesquisas nos/dos/com os cotidianos. In: ALVES, Nilda: OLIVEIRA, Inês Barbosa de (Org.). Pesquisa nos/dos/com os cotidianos das escolas - sobre redes de saberes. Petrópolis/RJ: DP et alii, 2008. p. 39-48.

ARROYO, Miguel G. Currículo, território em disputa. 5a edição. Petrópolis, RJ: Vozes, 2013.

BARONI, P. Apresentação. In: REIS, Graça; MARTINS, I. M. B. ; CAMPOS, M. S. N.; RODRIGUES, S. A.; RIBEIRO, T. (Org.) . Narrativas na/da pandemia. 1. ed. Rio de Janeiro: Ayvu, 2021. v. 1.

BENJAMIN, W. O narrador. Considerações sobre a obra de Nikolai Leskov. In: BENJAMIN, W. Obras escolhidas I: Magia e técnica, arte e política. 7. ed. São Paulo: Brasiliense, 1987.

BERTI et al.1 IN: BERTI, A; SOUZA, C. M.; NASCIMENTO, E. Diálogos com as famílias em tempos de isolamento social: a escola como território do comum. In: PONTES, Cassandra:; REIS, G. R. F. da S.; FREIRE, Sulamita Inácio (Org.). O colégio de aplicação da UFRJ diante do inédito: perspectivas femininas da escola em suspensão - Rio de Janeiro, RJ: Ayvu, 2021. p. 77-93.

CAMPOS, M. S. N. de; REIS, G. R F S. Os materiais narrativos e a reconfiguração dos currículos: desafios e possibilidades. Currículo sem Fronteiras, v. 19, n. 1, p. 396-417, jan./abr. 2019. Disponível em: https://www.curriculosemfronteiras.org/vol19iss1articles/campos-reis.pdf

CAMPOS, M, S, N, de. Desinvenções docentes na pandemia. IIn: REIS, Graça; MARTINS, I. M. B. ; CAMPOS, M. S. N.; RODRIGUES, S. A.; RIBEIRO, T. (Org.) . Narrativas na/da pandemia. 1. ed. Rio de Janeiro: Ayvu, 2021. v. 1. p. 157- 162

CARVALHO, L.; LEVY, M. IN: In: PONTES, Cassandra: REIS, G. R. F. da S.: FREIRE, Sulamita Inácio 
(Org.). O colégio de aplicação da UFRJ diante do inédito: perspectivas femininas da escola em suspensão

- Rio de Janeiro, RJ: Ayvu, 2021. p. 203- 218.

CERTEAU, Michel de. A invenção do cotidiano: 1. Artes de fazer. 12ª ed. Petrópolis: Vozes, 1994.

COUTINHO, Eduardo. O cinema documentário e a escuta sensível da alteridade. In ANTONACCI, Maria Antonieta e PERELMUTTER, Daisy (orgs). Projeto História - ética e história oral. S. Paulo: PUC/SP, abril/1997, (15): $165-191$.

GALEANO, Eduardo 1940 - O livro dos abraços / Eduardo Galeano; tradução Eric Nepomuceno. - 2 edição Porto Alegre - L\&PM, 2009.

LIMA, F. F. S. Como pensar a gestão da escola de educação infantil em um contexto de pandemia? In: REIS, Graça; MARTINS, I. M. B. ; CAMPOS, M. S. N.; RODRIGUES, S. A.; RIBEIRO, T. (Org.) . Narrativas na/da pandemia. 1. ed. Rio de Janeiro: Ayvu, 2021. v. 1.p. 91-100

MATURANA, Humberto. Emoções e linguagem na educação e na política. Tradução Jose Fernando Campos Fortes. Editora UFMG.. Belo Horizonte, 1999.

MENEZES, A. T. IN: In: PONTES, Cassandra; REIS, G. R. F. da S.; FREIRE, Sulamita Inácio (Org.). O colégio de aplicação da UFRJ diante do inédito: perspectivas femininas da escola em suspensão - Rio de Janeiro, RJ: Ayvu, 2021. p. 41-60

OLIVEIRA, I. B. Currículo e processos de aprendizagemensino: políticaspráticas educacionais cotidianas. Currículo sem Fronteiras, v. 13, n. 3, p. 375-391, set./dez. 2013.

OLIVEIRA, I. B. O currículo como criação cotidiana. Petrópolis: DP et Alli, 2012.

PRADO, G., FERREIRA, C. e FERNANDES, C. NARRATIVAS PEDAGÓGICAS E MEMORIAIS DE FORMAÇÃO: Escrita dos profissionais da educação? Revista Teias, v.12, n.26, p.143-153, set/dez 2011. Disponível em: https://www.e-publicacoes.uerj.br/index.php/revistateias/article/view/24216. acesso em 10 de setembro de 2021.

QUEIROZ, C.T; REIS, G. R. F.da S.; CAMPOS, M. S. N. de. In: PONTES, Cassandra; REIS, G. R. F. da S.; FREIRE, Sulamita Inácio (Org.). O colégio de aplicação da UFRJ diante do inédito: perspectivas femininas da escola em suspensão - Rio de Janeiro, RJ: Ayvu, 2021. p. 115 -144.

REIS, Graça Regina Franco da Silva; OLIVEIRA, I. B. . Sobre experiênciaspráticas e currículo menor: currículos praticadospensados nos cotidianos das escolas. In: LOPES, D.; OLIVEIRA, I. B. de; FREITAS, M. (Org.). Educação continuada, currículo e práticas culturais II. 1ed.Rio de Janeiro: DP et Alii, 2018, v. 2, p. 67-84.

SANTOS, Boaventura de Sousa. Para além do Pensamento Abissal: das linhas globais a uma ecologia de saberes. In: SANTOS, Boaventura de Sousa, MENESES, Maria Paula (Org.). Epistemologias do Sul. São Paulo: Cortez, 2010.

SANTOS. B. S. S. Para uma sociologia das ausências e uma sociologia das emergências, Revista Crítica de Ciências Sociais [Online], 63 | 2002. Disponível em: http://journals.openedition.org/rccs/1285, acesso em 10 de setembro de 2021.

SILVA, M. N. Sobre o percurso de me tornar uma professora das infâncias e os desafios enfrentados na docência em tempos de pandemia In: REIS, Graça; MARTINS, I. M. B. ; CAMPOS, M. S. N.; RODRIGUES, S. A.; RIBEIRO, T. (Org.) . Narrativas na/da pandemia. 1. ed. Rio de Janeiro: Ayvu, 2021. v. 1.p. 143-152

SOUZA, Elizeu Clementino. Outras formas de dizer: diálogos sobre pesquisa narrativa em/com Nilda Alves. Revista Teias, v.13 n.29 p.61-71. n.especial / 2012 Disponível em: https://www.epublicacoes.uerj.br/index.php/revistateias/article/download/24295/17274. acesso em 10 de setembro de 2021 


\section{Correspondência}

Graça Regina Franco da Silva Reis: Doutora e Mestre em Educação pelo ProPED/UERJ. É professora do Colégio de Aplicação (CAp) e do Programa de Pós Graduação em Educação (PPGE) da Universidade Federal do Rio de Janeiro. É líder do grupo de pesquisa "Conversas entre professorXs: alteridades e singularidades" (ConPAS/CAp/UFRJ) .Coordenadora do Projeto de pesquisa e extensão "Os materiais narrativos e a produção curricular: desafios e possibilidades". É coordenadora do GT 13 de Educação Fundamental da ANPED, e membro da ABdC/Associação Brasileira de Currículo.

E-mail: francodasilvareis@gmail.com

Orcid: https://orcid.org/0000-0002-2420-0985

Marina Santos Nunes de Campos: Doutora e Mestre em Educação pelo PROPED/UERJ. Possui graduação em Pedagogia pela UERJ. É professora do Colégio de Aplicação da UFRJ e coordenadora do Curso de Extensão Conversas sobre práticas nos Anos Iniciais do Ensino Fundamental.

E-mail: marinacampoz@gmail.com

Orcid: https://orcid.org/0000-0002-5204-7754

Ilana Maria Martins: Pedagoga pela Universidade Federal do Rio de Janeiro(UFRJ). Professora do Colégio de Aplicação da Universidade Federal do Rio de Janeiro (CAp/UFRJ). Mestranda em educação pelo Programa de Pós-Graduação da UFRJ (PPGE/UFRJ) na linha: Formação Docente, Linguagens e Subjetividades.

E-mail: ilana.ufrj@gmail.com

Orcid: https://orcid.org/0000-0002-1320-0226

Texto publicado em Currículo sem Fronteiras com autorização dos autores. 